\title{
Development of Jaundice Detection Approaches in Neonates
}

\author{
D.O.I-10.51201/12312 \\ https://doi.org/10.51201/12312
}

\author{
Priti V Bhagat ${ }^{*}$, Dr Mukesh M. Raghuwanshi ${ }^{2}$, Dr. Kavita $\operatorname{Singh}^{3}$, \\ Dr Sachin Damke ${ }^{4}$, Dr Syed Quazi ${ }^{5}$
}

1. $\mathrm{PhD}$ (Pursuing), Assistant Professor, Department of Computer Science \& Engineering DMIETR, Wardha, India;

2. PhD, Professor, G.H. Raisoni College of Engineering and Management, Pune, India;

3. PhD, Associate Professor, Department of Computer Technology, Yeshwantrao Chavan College of Engineering, Nagpur, India;

4. MBBS, MD, Professor, Department of Pediatrics,JNMC, Sawangi (M), Wardha, India;

5. MBBS, MD (Community Medicine), PhD (Community Medicine)

Director (R\&D), DMIMS (DU), Wardha, India

\begin{abstract}
Jaundice is one of the most common diseases that have a significant impact in the first few days of newborn life. Detection and regular monitoring of bilirubin, which is responsible for Jaundice, is an essential phase during the hyperbilirubinemia. In the literature, various clinical assessment methods of Jaundice are available. It motivates us to present a review of these clinical assessment methods in practice, along with their advantages and limitations. In this paper, we have discussed three widely used methods, such as visual assessment, total serum bilirubin and transcutaneous bilirubinometer. From the comparative analysis of these methods, it is concluded that the visual assessment is very subjective in nature, whereas, the total serum bilirubin method is still a gold standard method. The detailed analysis of the methods depicts that the correlation between this two total serum bilirubin and transcutaneous
\end{abstract}


bilirubinometer has enormous potential for improvement resulting in the enhancement in precision and accuracy of bilirubin measurement.

Keywords: Neonatal, Jaundice, bilirubin measurement, Bilirubinometer, Kernicterus

\section{INTRODUCTION}

Jaundice is amongst the most common conditions that occur in the newborn, is caused due to intensification of bilirubin in the blood. Bilirubin is a by-product produced due to the breakdown of red blood corpuscles (RBCs). It passes through the liver and excreted by the body in bile or urine. A higher level of bilirubin leads to the yellow discoloration of sclera and skin, which needs treatment of either phototherapy or exchange transfusion [1][2].

From the literature, it has been observed that around $70 \%$ of all the newborn and also a higher percentage of premature infants develop clinical Jaundice during the first few weeks of life[3]. The reason for Jaundice in a newborn is due to an increased breakdown of red blood corpuscles or decreased function of the liver [4]. Jaundice in the newborn can cause an additional effect such as Kernicterus, where bilirubin can accumulate in the brain and results in brain damage [2][3][4][5]. Figure 1 depicts the complete process of bilirubin formation. When the red blood corpuscles are a breakdown, it releases haemoglobin, which is further breakdown into heme and globin. Heme is finally converting into bilirubin [6].

Over the last several decades, many methods have been proposed for clinical assessment of bilirubin, each with distinct characteristics. From the reported literature, the three most common and clinical methods are namely, (i) visual assessment (VA), (ii) total serum bilirubin (TSB), and (iii) transcutaneous bilirubin (TcB) [7]. In visual assessment (VA), the estimation is done in the discernible manner, which is subjective, inaccurate and non-reliable. The measurement of the total serum bilirubin (TSB) is evaluated by measuring the bilirubin accurately present in blood through the pathological process, causing pain and time consuming. Lastly, transcutaneous bilirubin $(\mathrm{TcB})$ is anticipated as a non-invasive way of 
predicting total serum bilirubin and based on the principle of measurement of the yellowness of the skin by analysing the spectrum of light reflected by the baby's skin[7]. From the literature it is also observed that the regular monitoring of bilirubin is still a challenging issue and need of the day in the current scenario.

This motivates us to present a detailed survey of the various methods presented in the literature for clinical assessment of Jaundice in the context of the advantages and disadvantages of each and also analysing the impact of each. The main contribution of the paper is twofold. Firstly, it presents the detail and comparative analysis of the aforementioned methods, and secondly, it illustrates that the correlation between total serum bilirubin and transcutaneous bilirubinometer has immense potential for enhancement in precision and accuracy of the measurement bilirubin measurement.

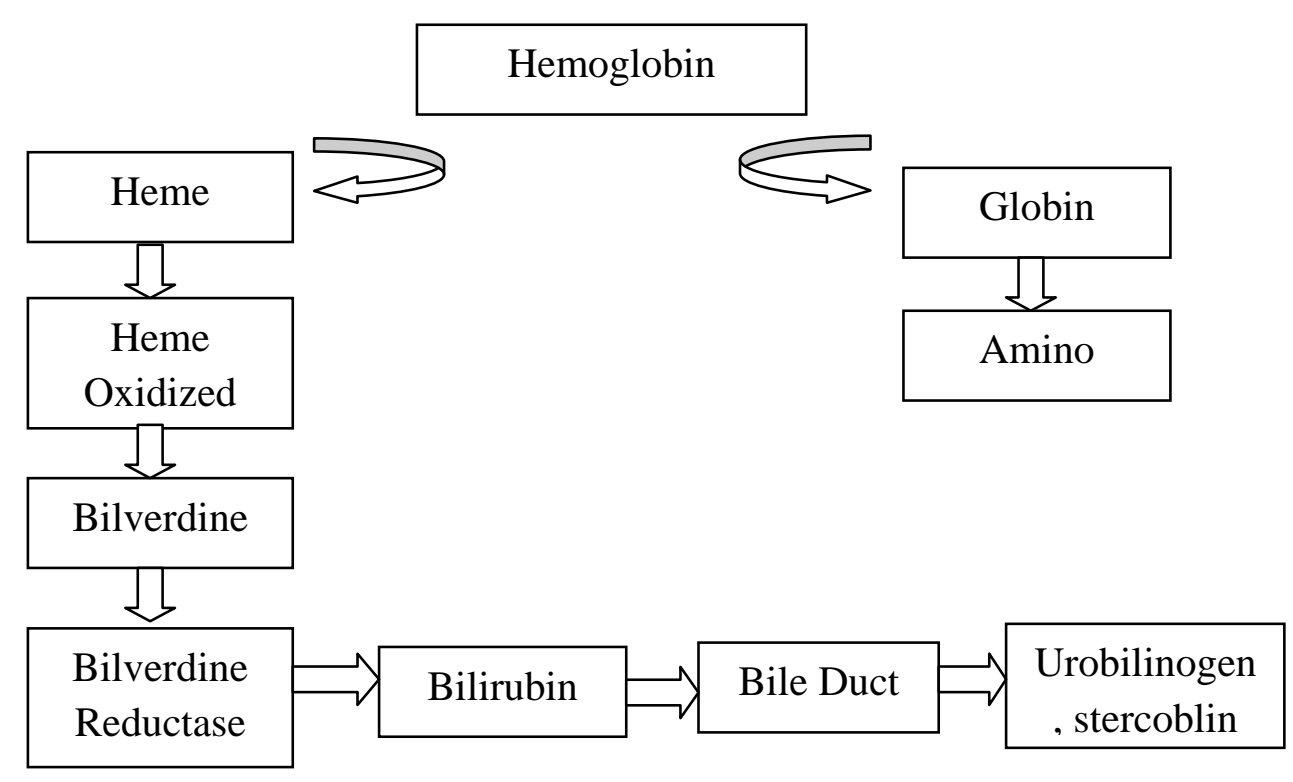

Figure 1: The process of Bilirubin formation[6]

\section{CLINICAL ASSESSMENT}

This section of the paper deliberates various clinical assessment methods necessary for Jaundice. Looking into the severity of the Jaundice and its impact on the health of a newborn, it is crucial that every newborn must be observed at an interval of 8 to 12 hours for Jaundice 
while in the hospital, or examine for jaundice between the third and seventh day after birth, when bilirubin levels usually peak. Apart from the medical process involved in Jaundice's assessment, Kramer's rule [8] presents a mechanism for the clinical assessment of Jaundice severity through the correlation of the different zones of the skin or area of the body as depicted in figure 2 either by VA, TSB, and TcB.

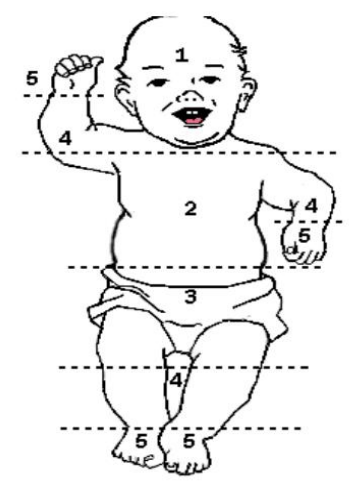

Figure 2: Zones of Kramer's Rule[5]

The protocol established by American Academy of Paediatrics(Figure 3) summarised the measurement of TSB and TcB in the first 24 hours after the visual estimation of Jaundice.[9] In subsequent sections, we present a detail description of each of the clinical assessment methods viz; VA, TSB, and TcB for better understanding.

\subsection{Visual Assessment}

Visual assessment has been recognised as a preliminary rapid detection method which generally starts with skin observation to get any medical assistance. Based on the skin colour or skin tone of neonates, in general there are two ways of doing a visual assessment, firstly, checking the yellowness or brown staining by pressing a finger gently on the notable area like forehead, chest, abdomen, arm or legs and observing the yellow colour in that area. Higher the yellowness of the skin depicts the possibility of Jaundice. Secondly, an inspection of sclera for yellowish or brown staining followed by an examination of the gums and inner lips for yellowish staining as a vital tool for neonates with dark skin colour [10]. 
The two ways of visual assessment listed in the above paragraph can be performed by observing the various areas of the body. Each area of the body marked as levels 1, 2, 3, 4, and 5 , as shown in figure 2 , have a different range of serum bilirubin, which helps in visual assessment of neonatal Jaundice. The various zones of a body of a newborn and related range of serum bilirubin are shown in table 1 . From table 1 , it is evident that palms and soles area of the body marked as level 5 have the highest serum bilirubin $(\geq 306 \mu \mathrm{mol} / \mathrm{L})$ and $(\geq 18$ $\mathrm{mg} / \mathrm{dL}$ ). This higher range of serum bilirubin shows that palm area plays a vital role in visual assessment of Jaundice. Similarly, other areas have their importance in visual assessment of Jaundice according to serum bilirubin range, with head and neck portion with the least range of serum bilirubin. All newborn with the risk factor of Jaundice must perform transcutaneous bilirubin or serum bilirubin measurement[11].

Table 1. The Visual Assessment of Neonatal Jaundice (NNJ) (Kramer's rule) [8]

\begin{tabular}{|c|c|c|c|}
\hline \multirow{2}{*}{ Area of the Body } & \multirow{2}{*}{ Level } & \multicolumn{2}{|c|}{ Range of serum bilirubin } \\
\cline { 3 - 4 } & & $\boldsymbol{\mu} \mathbf{m o l} / \mathbf{L}$ & $\mathbf{~ m g / d L}$ \\
\hline Head and neck & 1 & $68-133$ & $4-8$ \\
\hline Upper trunk (above the umbilicus) & 2 & $85-204$ & $5-12$ \\
\hline Lower trunk and thighs (below the \\
umbilicus) & 3 & $136-272$ & $8-16$ \\
\hline Arms and lower legs & 4 & $187-306$ & $11-18$ \\
\hline Palms and soles & 5 & $\geq 306$ & $\geq 18$ \\
\hline
\end{tabular}

Although, both the ways of visual assessment mentioned above might be efficient at initial stage, but the visual assessment methods are subjective in nature leads to error in decision for the medical treatment of Jaundice. The other characteristics of visual assessment also make it non-quantification scheming and challenging in case of dark skin colour. To overcome the 
challenges of visual assessment methods, a need for a direct mechanism to measure the ilirubin level that is further discussed in the forthcoming section 2.2 . 


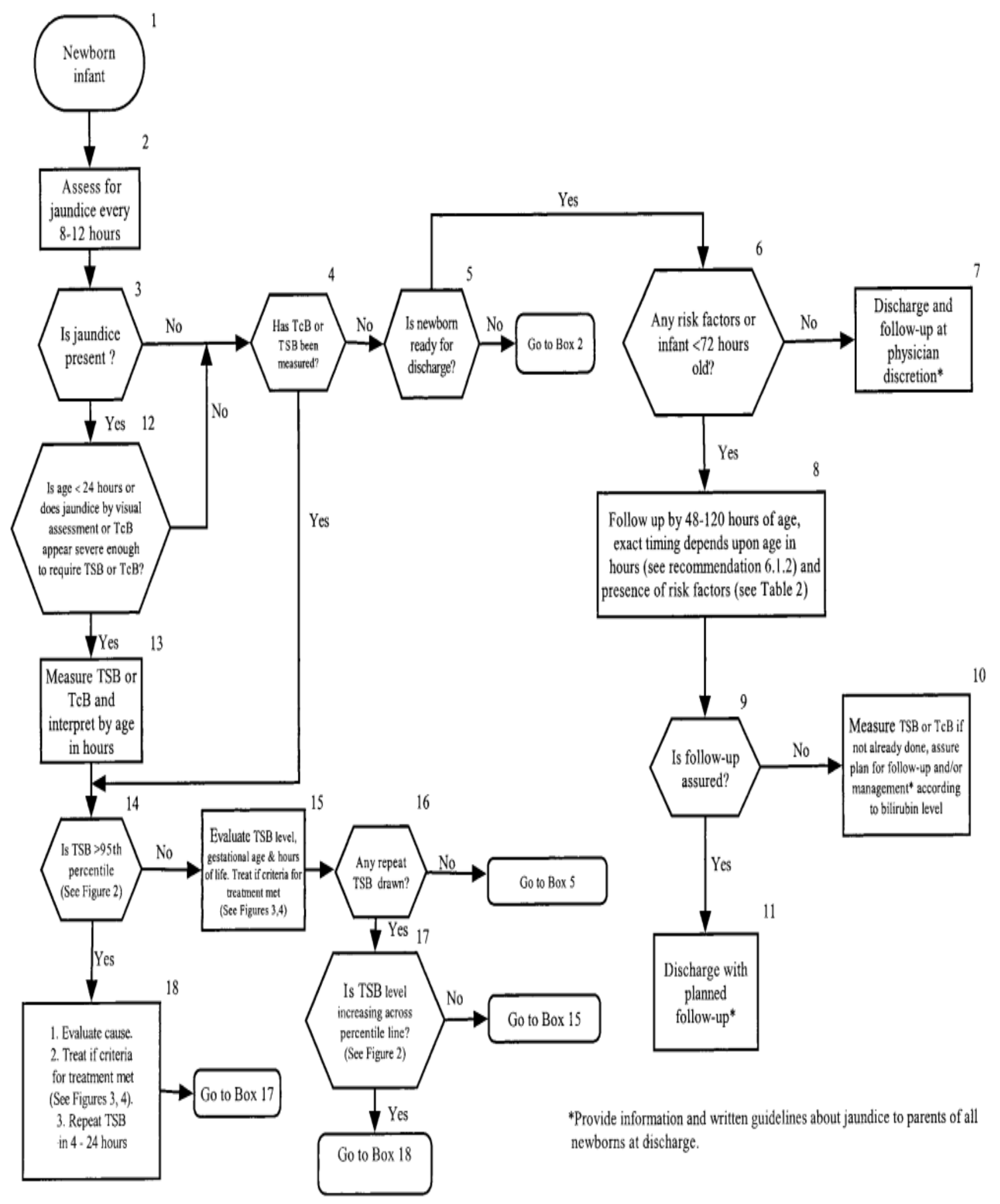

Figure 3: Flowchart for the management of Jaundice in the newborn[9] 


\subsection{Total Serum Bilirubin Test}

Total Serum Bilirubin (TSB) method measures the bilirubin content from the blood test directly. It is an obtrusive system and additionally precise, progressive strategy of bilirubin measurement. In literature, it has been reported as the standard criterion in clinical practices. The human services supplier refers a specific chart to gauge this bilirubin substance called Bhutani nomogram[12]. It determines the age (in hours ' $h$ ') of infants, long stretches of development and level of bilirubin $(\mathrm{mg} / \mathrm{dL})$. The risk zone of nomogram is shown in figure 4 . From the graph shown in figure 4 it is evident that, risk designation of term and near-term well newborn based on their hour-specific serum bilirubin values. The high-risk zone is designated by the 95th percentile track. The intermediate-risk zone is subdivided to upperand lower-risk zones by the 75 th percentile track. The low-risk zone has been electively and statistically defined by the $40^{\text {th }}$ percentile track. (Dotted extensions are based on $<300$ TSB values/epoch)[9] [12].

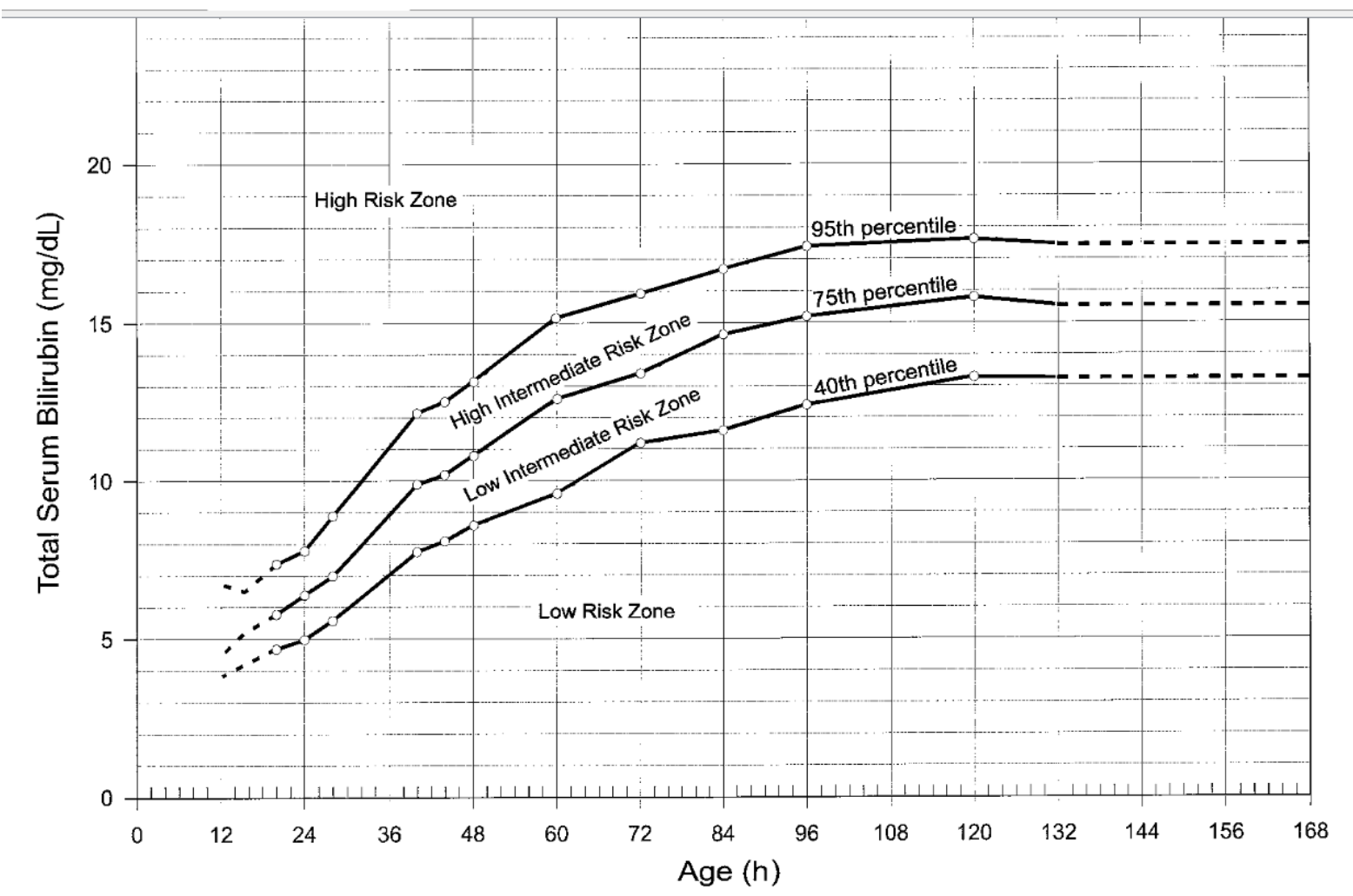

Figure 4: Risk zone of Bhutani nomogram [12] 
There is large number of TSB methods reported in literature. Among all these methods, the most commonly used one to examine TSB are Diazo method, High-performance Liquid Chromatography (HPLC), and Direct Spectrophotometry[13]. In the forthcoming subsections, we briefly discuss each of the listed methods used for bilirubin measurement.

\subsubsection{Diazo Method}

It is a conventional TSB method of measuring bilirubin. In the Diazo method, the coloured compound azobilirubin is formed by reacting bilirubin with a Diazo reagent. Various additional chemicals can accelerate the Diazo reaction. In the presence of a surfactant, Diazo reagent forms a couple with total bilirubin to form azobilirubin. The increase in the level of absorbance at $548 \mathrm{~nm}$ due to azobilirubin is directly proportional to the total bilirubin concentration [13] [14][15].

The advantages of this method are (i) not affected by changes in $\mathrm{pH}$ value, (ii) it maintains the optical sensitivity even at low bilirubin concentration, (iii) insensitive to high protein concentrations[14].

The linearity limit of diazo methods is $20 \mathrm{mg} / \mathrm{dl}$. Difficulties for using diazo method arise from two leading causes: the use of unsatisfactory artificial standards for matching the colour; and the presence of extraneous coloured substances[13].

\subsubsection{HIGH-PERFORMANCE LIQUID CHROMATOGRAPHY (HPLC)}

Another TSB method, that is, High-performance Liquid Chromatography, is applied to bifurcate and quantify the tokens of bilirubin such as unconjugated bilirubin, monoconjugate bilirubin, and deconjugated bilirubin. This method has been widely used in research to get information about bilirubin types available in the blood. The limitation of this method is that it doesn't provide any additional clinical data and expensive[13][14][15]. The HPLC method is more accurate and sensitive than the Diazo method for the prediction of bilirubin and conjugates in serum and other biological fluids [16]. 


\subsubsection{DIRECT SPECTROPHOTOMETRY}

Direct Spectrophotometry is a simple and straightforward strategy to quantify bilirubin fixation in babies. This technique relies on the bilirubin absorbance at $454 \mathrm{~nm}$ and haemoglobin absorbance at 454 and $528 \mathrm{~nm}$. The difference between the haemoglobin absorbance is assimilated to clear the haemolysis impact. The resultant worth is corresponding to bilirubin focus. The burdens of this technique are that it retains different colours like carotenoids at $454 \mathrm{~nm}$. Henceforth, two to multi weeks of infants[13][14][15].

From the above discussion on various methods of TSB undoubtedly, it is a direct method of bilirubin measurement. Nonetheless, various limitations associated with TSB are invasive, time consuming and may delay the post identification treatment where clinical laboratories are unavailable. The challenging issues with TSB motivated another feasible method for Jaundice screening, as discussed in the next subsequent section 2.3.

\subsection{Transcutaneous Bilirubinometer}

It is imperative to limit the amount of blood that the newborn loses through blood sampling. Therefore, it is critical to diminish the number of blood tests as much as possible[1]. The most feasible option for Jaundice prediction is the use of a transcutaneous bilirubinometer. Transcutaneous bilirubin $(\mathrm{TcB})$ assurance investigates the light reflected by the skin and subcutaneous tissues with a specific wavelength [17]. It is a non-invasive mode for Jaundice screening. It is a stress-free, simple and suitable method for measuring the bilirubin level[17]. Transcutaneous bilirubinometer correspond better results with serum bilirubin levels in newborn and premature infants. However, the mean contrasts among the hyperbilirubinemia level estimated by transcutaneous bilirubinometer and TSB are enormous when the bilirubin levels surpass $205 \mu \mathrm{mol} / \mathrm{L}(12 \mathrm{mg} / \mathrm{dL})$ in newborn [18]. An additional drawback of transcutaneous meters is that their availability and accessibility in under-developing nations. Likewise, there is clashing proof concerning the affectability of TcB utilization in dark colour 
neonates $[8][19][20][21]$. In literature, many transcutaneous meters have been reported and have been used for experimentation. In this context, it becomes the foremost task to understand a few of the widely used transcutaneous meters.

Among many of the commercially available transcutaneous meters, Dragor JM-105, Philips BiliChek are the widely used ones. The Drager JM-105 is an advanced version of KonicaMinolta JM-103; it uses a dual optical path with two wavelengths to measure transcutaneous bilirubin, whereas multiple wavelengths are used by BiliChek, between $400 \mathrm{~nm}$ to $760 \mathrm{~nm}$. It uses various wavelengths to eliminate the effect of haemolysis and skin pigmentation for accurate $\mathrm{TcB}$ measurements[22]. TcB, for the most part, might be influenced by the pigmentation of skin and thickness. Then again, TSB or TcB mirrors the intravascular bilirubin concentration[23].

As mentioned by Ebbesen et. al. [1] and Olusanya et. al. [24] US Food and Drug Administration has approved the $\mathrm{TcB}$ approximations for clinical use. Although $\mathrm{TcB}$ approximations give sensibly exact evaluations, an absence of relationship amongst $\mathrm{TcB}$ and TSB during phototherapy has also been observed [25][26]. The BiliChek and JM-103 or JM105 bilirubinometers fundamentally overestimate TSB in pigmented neonates and may bring about pointless or unnecessary medications[24][25]. The deviation between the estimation information obtained by the BiliChek and TSB results in a general increment in babies with moderately high TSB values, particularly in non-Caucasian infants [26][27]. A bilirubinometer is expected to reduce the error due to pigmented skin when inspecting for high TSB values or experiencing phototherapy. Also, it was identified with precision is an estimation locale with progressing postnatal age, dependable location for TcB estimations change[28]. Conceicao et. al., contended that TcB estimated on the sternum had higher exactness than that deliberate on the forehead [29]. Kramer's standard might survey the seriousness of Jaundice, with changes in skin colour typically nearby a head-to-toe way as 
intradermal bilirubin testimony advance.

Further, Natalie Purcell et al., supported the theory that the cephalocaudal movement of Jaundice in infants is due to narrowed bloodstream [30]. Authors stated that, in an initial couple of days, the blood supply for head and a proximal fragment of the body is higher, resulting in high temperature and expanded bilirubin testimony. Ongoing additions in spectroscopic optical intelligibility tomography could be utilized to research the procedures of nearby bilirubin extravasation into the skin [2].

Later, Keahey et. al., designed BiliSpec, another screening tool for prediction of bilirubin level [31]. It is an inexpensive bilirubin reader, which works with a disposable lateral flow card. A blood sample is taken on an outboard flow card to estimate the total bilirubin and then placed on BiliSpec. (Figure 5)

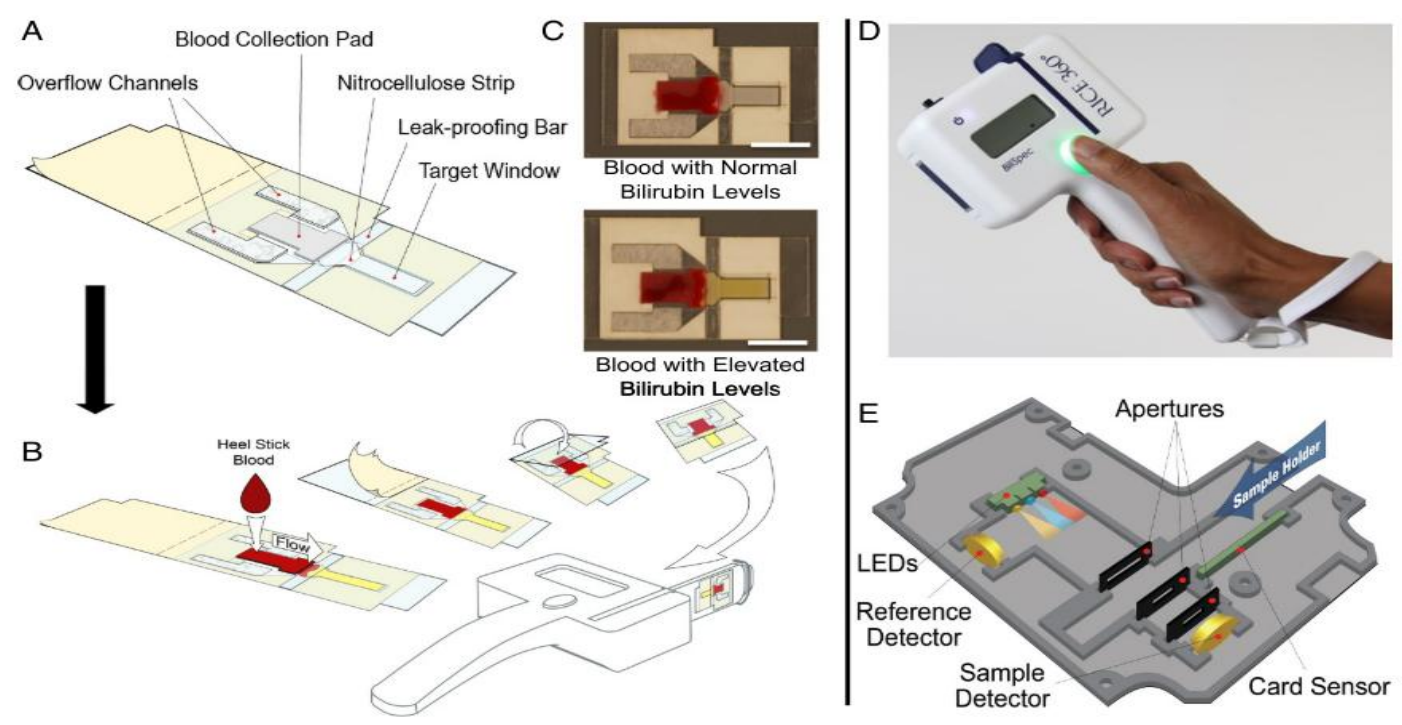

Figure 5: BiliSpec lateral flow card and reader. (A) Diagram of the lateral flow card components. To use the card, blood was applied to the collection pad, the protective paper was removed from the adhesive-coated acetate, and the card is folded to seal blood inside. (B) Plasma flows down to the distal tip of the card before being inserted into the reader for measurement. (C) Representative photographs of sealed lateral flow cards following the application of blood with normal and elevated TSB levels. (Scale bar, $1 \mathrm{~cm}$.) (D) Photograph 
of the hand-held reader. (E) Diagram illustrating the internal optical and electronic layout of the reader [14][31].

A completely new bilirubin measuring device called Icterometer is used to predict the bilirubin level was presented in [32]. Icterometer is a paper containing four yellow colour strips. The concept was to use 5, 10, 15 and $20 \mathrm{mg} / \mathrm{dL}$ for making four yellow strips of the Icterometer, as shown in figure 6 . These yellow strips were gently pressed on the nose of the newborn to forecast the bilirubin attentiveness.
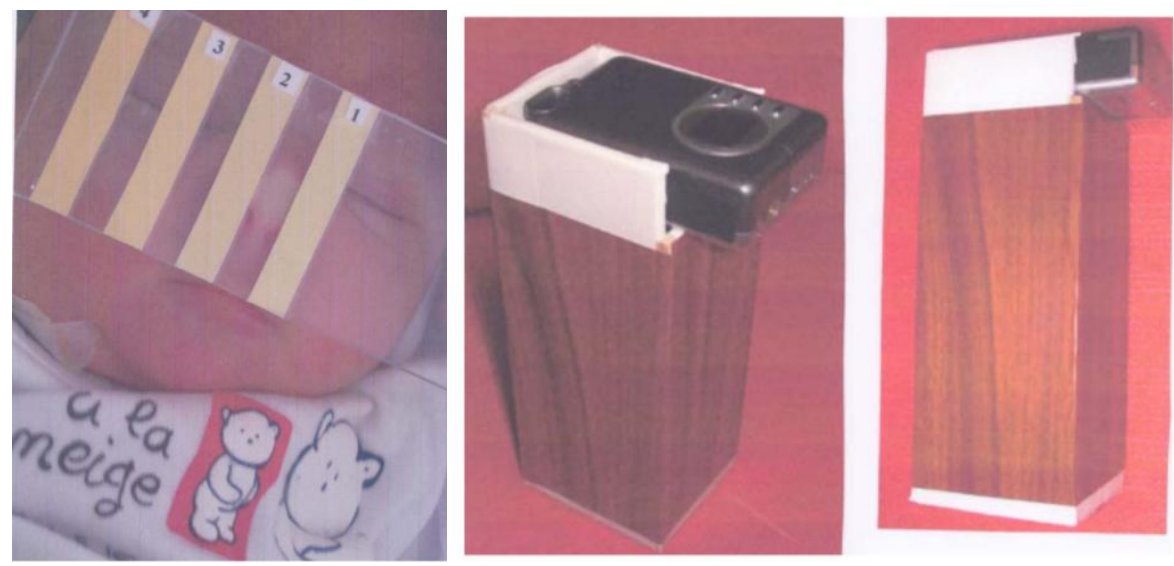

Figure 6: Use of color strip on the nose of the infant [32]

The first few bilirubin measuring devices discussed in the earlier section were explicitly designed for neonates. Therefore, a Jaundice prediction tool for an initial couple of days, especially for mothers and caretakers was designed that was called as Bilistrip. It is twocolour Icterometer (Light Yellow or Dark Yellow). Keep Bilistrip on the blanched skin of baby's nose and matched the colour with the card as sown in figure 7. The Light Yellow card projected the absence of significant Jaundice, whereas the Dark Yellow described the existence of considerable Jaundice[33]. Furthermore, Anne et. al., presented a new Icterometer named Bili-ruler using advanced digital colour processing [34]. Digitally standardized and calibrated archival-quality paper colour strips of increasing yellow hue; 
numbered 1 through 6 is used to construct Bili-ruler, as shown in figure 8 .
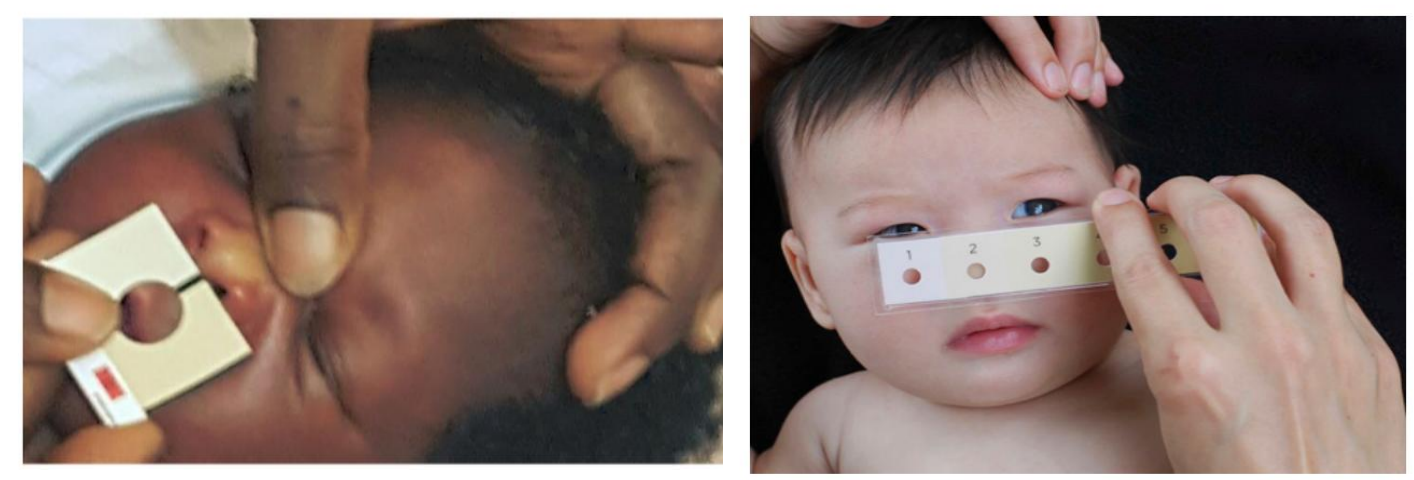

Figure 7: Baby tested with Bilistrip[33] Figure 8: Use of Bili-ruler on nose ofinfant[34]

During the later years of research, another potential screening tool to determine Jaundice using digital photographs of the sclera, capture through a smartphone was presented in [35]. The colour of sclera and skin changed due to an increased level of bilirubin. They processed the pixel colour values obtained from the image of the sclera of the infant to predict the TSB level. TSB levels above $205 \mu \mathrm{mol} / \mathrm{L}$ can be predicted by this method with a sensitivity of 1.00 and specificity of 0.50 . The influence of ambient light and room light, which can vary the results. Figure 9 shows how sample images were captured with the colour chart. On the other hand, Outlaw et. al., used images of sclera capture through a smartphone application, neoSCB, without the use of a colour calibration card [36].

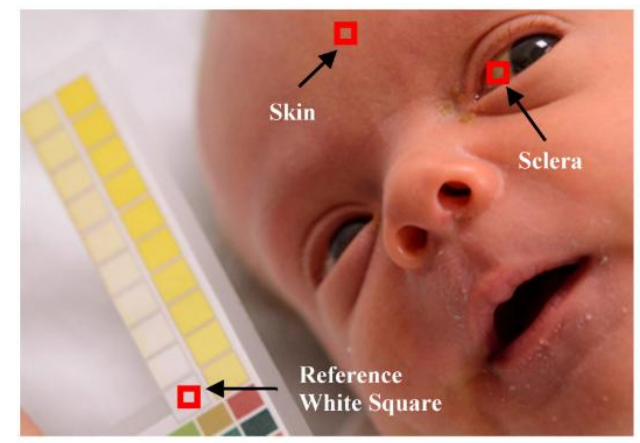


Figure 9: Sample image collected in the hospital using a colour chart Following the concept of a digital image, D Leartveravat et. al., used a digital photograph of the sternum of the neonate to measure the transcutaneous bilirubin level [37]. $70 \%$ of lightness was maintained while capturing an image with the control paper. The value of $\mathrm{Y}$ and M by the CMYK system used to establish a correlation with total serum bilirubin. Aydin et. al., design a non-invasive smartphone-based application for the prediction of neonatal Jaundice [38]. They work with images captured through the smartphone with a colour calibration card. Advanced image processing techniques and machine learning regression are applied to images to predict the presence of Jaundice. For this study, they have chosen 40 Jaundiced and 40 healthy babies. They achieved the correlation rate of $85 \%$ with TSB. Further, Taylor et. al., presented an extended and new smartphone application to predict neonatal Jaundice called BiliCam [39]. This application works with digital images taken with a smartphone with a colour calibration card. Pixel information was extracted from images using specialized software. Features were identified through Machine learning and regression analysis. Instead a different method for bilirubin predictions from camera captured skin colour was proposed by Falk et. al. [40]. Gaussian process regression (GPR) was used for colour correction and neural network-based regression models for bilirubin prediction.

Another smartphone-based application was designed by Padidar et. al., to estimate the bilirubin level [18]. He used a colour calibration card, and a 100X zoom microscope was used to capture an image. Colour calibration card was used to reduce the effect of ambient lighting conditions. The various lens of all brands of Android smartphone can be calibrated using a colour calibration card. As the processing of this application is offline, users can voluntarily work with the app without any limitations. Figure 10 shows the sample imaging technique. 


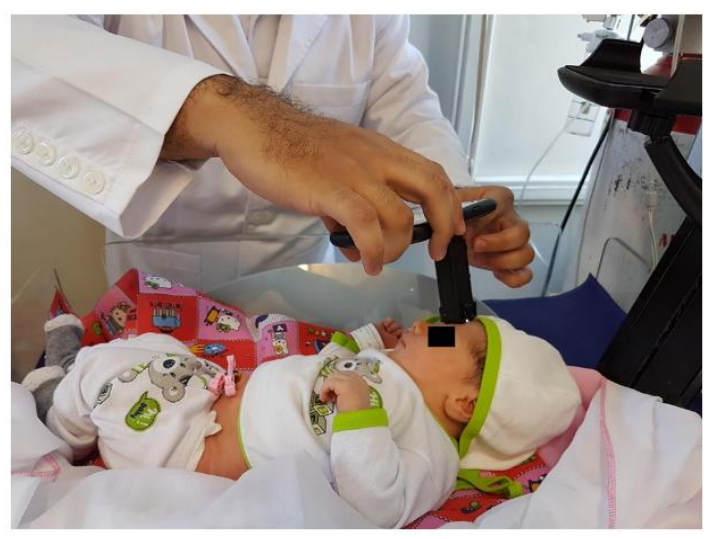

Figure 10: Sample Imaging Technique used by Padidar et. al.[18]

\section{DISCUSSION}

A considerable literature is available focusing on the various invasive methods and noninvasive methods to detect bilirubin concentration in neonates[14]. Although, few of the studies are more than 50 years old, nevertheless, serves the basis of bilirubin identification and cannot disallow its contribution in the field of neonatal Jaundice. On the other hand, the current state of literature focuses on the evaluation of the best technique and comparison of two or more methods. Quantification of TSB methods is still a criterion and medically proven method to detect bilirubin level. The limitations associated with TSB are invasive, time consuming and may delay the post identification treatment where clinical laboratories are unavailable. Hence, the most feasible option for Jaundice screening is a transcutaneous bilirubinometer[17]. The different research group works on the comparison of several TcB devices with a different number of subjects to be considered under study. Some of the notable literature is tabulated in table 3 with linear correlation $r$ values.

Robertson et. al. evaluated the significance of the colour of skin in case of JM-102 meter $(p=0.002)$ while in case of BiliCheck $(p=0.890)$ it is non-significant[25]. It specifies the discrepancy associated with Bilicheck in terms of skin colour is fewer to predict TSB. The BiliCheck meter uses multiple wavelengths to reduce the effect of melanin and haemoglobin on the estimation of bilirubin[25]. In one of the studies at All India Institute of Medical 
Sciences (AIIMS), using Bilicheck, the sensitivity and specificity of the meter to pick up bilirubin $>13 \mathrm{mg} / \mathrm{dL}$ was $69 \%$ and $89.3 \%$ respectively. However, the sensitivity was lower at higher cut-offs [41].

Bilistick is a way to predict the TSB level. The Bilistick achieved 99\% accuracy and 100\% sensitivity to predict laboratory TSB of $\geq 80 \mu \mathrm{mol} / \mathrm{L}$ and $360 \mu \mathrm{mol} / \mathrm{L}$ at Bilistick TSB levels of $\geq 55 \mu \mathrm{mol} / \mathrm{L}$, and $\geq 315 \mu \mathrm{mol} / \mathrm{L}$, respectively[42]. The combined coefficient of correlation of TSB between the Bilistick and laboratory methods is $r=0.901$, which was lower than that reported by Coda Zabetta et. al.[43].

BiliSpec achieves a Pearson's correlation coefficient of $r=0.973$ when establishing an agreement between the reference standard, TSB level measured, and test set[31].

Another subjective method for predicting Jaundice is Icterometer in which yellow colour strip with a predefined indication of bilirubin is employed. Bilistrip is one of the commercially available icterometers. Olusanya et. al. examine Bilistrip and found sensitivity of $91 \%$, specificity of $24 \%$, PPV of $32 \%$, and NPV of $88 \%$ for predicting TSB >=12mg/dL; and sensitivity of $100 \%$, specificity of $21 \%$, PPV of $7 \%$, and NPV of $100 \%$ for TSB $>=17 \mathrm{mg} / \mathrm{dL}$ [33]. In another study, by Schumacher et.al a cut-off of $>=2.5$ is observed for light pigmented infants post-discharge with affectability of $73 \%$, explicitness of $65 \%$, PPV of $44 \%$, and NPV of $87 \%$ for recognizing neonates with TSB >=12 mg/dL; and affectability of $100 \%$, particularity of $58 \%$, PPV of $12 \%$, and NPV of $100 \%$ for TSB $>=17 \mathrm{mg} / \mathrm{dL}[44]$. As Bilistrip is an exclusively made to use on the nose of infant's, therefore it is challenging to compare results from different locations on the infant's body such as forehead, cheek, gum or sternum [33]. The standardization of Icterometer is difficult as the bilirubin level among the infants was normally low in the first two days of life, and it may not effectively reflect corresponding TcB or TSB values. The rapidly rising TSB was not accurately captured by Bilistrip, as there is not a correlation between the rate of cutaneous bilirubin deposition and 
the rate of rising in TSB. Still, Bilistrip offers a more straightforward alternative method to the already available multi-colour Icterometers as a potential decision-making tool to assist timely identification of Jaundice by mothers before the commencement of bilirubin encephalopathy[33].

There are some advanced methods which use image processing concepts to predict the value of TSB using a digital image of neonate's skin or sclera. BiliCam is another commercial product based on such image processing methods which use an image of neonates with colour calibration card, captured through Android smartphone application. The BiliCam can recognize neonates with high TSB level with sensitivities of $84.6 \%$ and $100 \%$, respectively, whereas its specificities were $75.1 \%$ and $76.4 \%$, respectively. Taylor et. al. found correlation coefficient value as 0.91 for BiliCam predicted bilirubin level and the paired TSB level[39]. From this, it is clear that image processing tools like Bilicam had accuracy for predicting TSB and TcB with some standardization. However, race and ethnicity of the neonates may influence the results of BiliCam [39]. The logical extension of BiliCam is designing the smartphone base application one of the remarkable apps is designed by Padidar et. al. [18]. He found Pearson correlation as 0.479 with the TSB values. Bilirubin level less than 10 $\mathrm{mg} / \mathrm{dL}$ estimated with the sensitivity of $68 \%$ and specificity of $92.3 \%$ and the bilirubin levels less than $15 \mathrm{mg} / \mathrm{dL}$ estimated with the sensitivity of $82.1 \%$ and specificity of $100 \%$ [18].

On the same background, the work presented by Leung et. al.[35], used digital image of the sclera of neonates to predict the value of TSB. They have used two-color metrics: blue chromaticity in the native RGB space and the newly-defined Jaundice Eye Color Index (JECI) in the Commission Internationale de l'Elcairage (CIE) XYZ space. Both color matrix shows a strong correlation with TSB, i.e., ( -0.73 and 0.73$)$ respectively; and $\mathrm{p}<0.01$, the advantage of using JECI is that the CIE XYZ space is a reference colour space containing all possible colours and thus it makes device-independent. 
Table 2 shows evaluations between plasma/serum bilirubin and non-invasive transcutaneous bilirubinometry from past forty-five years literatures. While, Table 3 shows the results for different transcutaneous bilirubinometers for Jaundice prediction from the available literature. As can be seen, the sensitivity, specificity, positive and negative predictive values varied among the studies. This could be due to the heterogeneity of the study populations and the age of the newborn at the time of the measurements [45].

Table 2: Comparison of Various Proposed TcB Techniques Reviewed by Carceller et. al. and our Group 43

\begin{tabular}{|c|c|c|c|c|c|c|}
\hline $\begin{array}{c}\text { Proposed } \\
\text { TcB } \\
\text { Techniques }\end{array}$ & Year & $N$ & Method & Body Site & $\begin{array}{c}\text { Pearson's } \\
\text { linear } \\
\text { correlation, } \\
r(\mathbf{n})\end{array}$ & $\begin{array}{c}\text { Bland- } \\
\text { Altman } \\
\text { test: mean } \\
\text { difference } \\
- \\
\pm \mathrm{SD} \\
(\mu \mathrm{mol} / \mathrm{L})\end{array}$ \\
\hline $\begin{array}{c}\text { Chaibva et. } \\
a l,{ }^{44}\end{array}$ & 1974 & 55 & Icterometer & Nose & 0.96 & NA \\
\hline $\begin{array}{c}\text { Yamanouchi } \\
\text { et. } a{ }^{45},\end{array}$ & 1980 & 66 & Minolta & Forehead & 0.93 & NA \\
\hline \multirow{2}{*}{$\begin{array}{c}\text { Schumacher } \\
\text { et. al. }\end{array}$} & \multirow{2}{*}{1985} & \multirow{2}{*}{106} & Icterometer & Nose & 0.63 & $\mathrm{NA}$ \\
\hline & & & Minolta & Forehead & 0.74 & NA \\
\hline $\begin{array}{l}\text { Yamauchi } \\
\text { et.al. }^{43}\end{array}$ & 1988 & 336 & Minolta & Forehead & 0.93 & $\mathrm{NA}$ \\
\hline $\begin{array}{c}\text { Gupta } e t . \\
\text { al. }{ }^{47}\end{array}$ & 1991 & 161 & Icterometer & Nose & 0.99 & NA \\
\hline $\begin{array}{c}\text { Linder } \text { et. } \\
\text { al. }^{48}\end{array}$ & 1994 & 123 & Minolta 101 & Sternum & 0.96 & NA \\
\hline $\begin{array}{c}\text { Knudsen } e t . \\
a l .{ }^{49}\end{array}$ & 1996 & 150 & Minolta 101 & Forehead & 0.78 & NA \\
\hline Tan et. al., ${ }^{50}$ & 1996 & 542 & Minolta & Sternum \& Forehead & 0.8 & NA \\
\hline
\end{tabular}




\begin{tabular}{|c|c|c|c|c|c|c|}
\hline $\begin{array}{c}\text { Tayaba et. } \\
\text { al. },^{51}\end{array}$ & 1998 & 900 & $\begin{array}{l}\text { Chromatics } \\
\text { Colormate III }\end{array}$ & $\begin{array}{l}\text { right or left cheek, } \\
\text { back, forehead, chest }\end{array}$ & 0.96 & NA \\
\hline $\begin{array}{l}\text { Rubaltelli et. } \\
\text { al. }^{52}\end{array}$ & 2001 & 210 & BiliCheck & Sternum \& Forehead & 0.89 & $17.8 \pm 77.0$ \\
\hline $\begin{array}{c}\text { Wong et. } \\
\text { al. }^{53}\end{array}$ & 2002 & 64 & BiliCheck & Forehead & NA & $4 \pm 67.9$ \\
\hline $\begin{array}{c}\text { Kazmierczak } \\
\text { et. al., }{ }^{54}\end{array}$ & 2004 & 95 & BiliCheck & Forehead & NA & $0.26 \pm 54.5$ \\
\hline $\begin{array}{c}\text { Carceller et. } \\
a_{l .}{ }^{43}\end{array}$ & 2006 & 178 & BiliCheck & Forehead & 0.78 & $\begin{array}{l}1.5[-50.4 \\
\text { to }+47.5]\end{array}$ \\
\hline $\begin{array}{l}\text { Leartveravat } \\
\text { S. et. al. }{ }^{37}\end{array}$ & 2009 & 61 & $\begin{array}{c}\text { Digital } \\
\text { photography }\end{array}$ & Sternum & 0.86 & NA \\
\hline $\begin{array}{l}\text { Vandermeer } \\
\text { B. et. al. }{ }^{20}\end{array}$ & 2013 & 16,10 & $\begin{array}{c}\text { BiliCheck, JM- } \\
\text { 102/103 }\end{array}$ & Forehead, Sternum & $\begin{array}{l}0.83(n=16), \\
0.83(n=10)\end{array}$ & $\begin{array}{c}0.06 \pm \\
29.46(\mathrm{n}= \\
912), 3.80 \\
\pm 24.06(\mathrm{n} \\
=265)\end{array}$ \\
\hline $\begin{array}{c}\text { Lilian de } \\
\text { Greef et. al. } \\
55\end{array}$ & 2014 & 100 & $\begin{array}{c}\text { Digital } \\
\text { photography }\end{array}$ & Sternum \& Forehead & 0.84 & NA \\
\hline $\begin{array}{l}\text { Leung T.et. } \\
\text { al. }^{56}\end{array}$ & 2015 & 110 & $\begin{array}{c}\text { Digital } \\
\text { photography }\end{array}$ & Sclera & 0.75 & $\begin{array}{l}0.00 \pm \\
41.60\end{array}$ \\
\hline $\begin{array}{c}\text { Aydin M. et. } \\
\text { al. }^{38}\end{array}$ & 2016 & 80,45 & $\begin{array}{c}\text { Digital } \\
\text { photography }\end{array}$ & $\begin{array}{c}\text { Skin (Normalized), } \\
\text { Skin }\end{array}$ & $\begin{array}{l}0.80(n=80), \\
0.85(n=40)\end{array}$ & $\begin{array}{c}0.01 \pm \\
38.61 \\
0.011 \pm \\
38.40\end{array}$ \\
\hline $\begin{array}{c}\text { Taylor J. et. } \\
\text { al. }^{39}\end{array}$ & 2017 & 530 & $\begin{array}{c}\text { Digital } \\
\text { photography }\end{array}$ & Skin & 0.91 & $\begin{array}{c}\text { mean } \pm 3.6 \\
\mathrm{mg} / \mathrm{Dl}\end{array}$ \\
\hline $\begin{array}{c}\text { Falk H. H. et. } \\
\text { al. }^{40}\end{array}$ & 2018 & 484 & $\begin{array}{c}\text { Digital } \\
\text { photography }\end{array}$ & Skin & 0.92 & $\begin{array}{c}\text { mean } \\
\text { value } \pm 50\end{array}$ \\
\hline $\begin{array}{l}\text { Rizvi M. et. } \\
\text { al. }{ }^{57}\end{array}$ & 2018 & 100 & $\begin{array}{c}\text { Digital } \\
\text { photography }\end{array}$ & Conjunctiva of eyes & 0.73 & NA \\
\hline
\end{tabular}




\begin{tabular}{|c|c|c|c|c|c|c|}
\hline $\begin{array}{c}\text { Munkholm S. } \\
\text { et. al. }{ }^{58}\end{array}$ & 2018 & 64 & $\begin{array}{c}\text { Digital } \\
\text { photography }\end{array}$ & Skin & $0.59,0.48$ & NA \\
\hline $\begin{array}{c}\text { Outlaw F. et. } \\
\text { al. }^{59}\end{array}$ & 2019 & 51 & $\begin{array}{c}\text { Digital } \\
\text { photography }\end{array}$ & Sclera & 0.75 & $\begin{array}{c}0.00 \pm \\
1.96\end{array}$ \\
\hline $\begin{array}{c}\text { Padidar P. et. } \\
\text { al. }{ }^{18}\end{array}$ & 2019 & 113 & $\begin{array}{c}\text { Digital } \\
\text { photography }\end{array}$ & Forehead & 0.47 & NA \\
\hline $\begin{array}{c}\text { Halder A. et. } \\
\qquad a l .{ }^{60}\end{array}$ & 2019 & 1033 & Spectrophotometry & Thumbnail & 0.95 & mean \pm 34.2 \\
\hline \multirow{2}{*}{$\begin{array}{l}\text { Lee A. et. } a l \text {. } \\
\qquad 34\end{array}$} & \multirow{2}{*}{2019} & \multirow{2}{*}{790} & \multirow{2}{*}{ Bili-ruler } & \multirow{2}{*}{ Nose } & TcB: 0.76 & \multirow{2}{*}{$\begin{array}{c}0.03 \pm 1.95 \\
\mathrm{mg} / \mathrm{dL} \\
(n=284)\end{array}$} \\
\hline & & & & & TSB: 0.78 & \\
\hline
\end{tabular}


Table 3: Sensitivity, Specificity, Positive and Negative Predictive Values of Non-invasive Transcutaneous Bilirubinometry Literature Reviewed by Carceller et. al. and our Group $^{43}$

\begin{tabular}{|c|c|c|c|c|c|c|c|c|c|}
\hline Author & Year & $N$ & $\begin{array}{l}\text { Gestational } \\
\text { age(weeks) }\end{array}$ & Device & $\begin{array}{l}\text { Serum } \\
\text { cut-off }\end{array}$ & $\begin{array}{c}\text { Sensitivity } \\
\%\end{array}$ & $\begin{array}{c}\text { Specificity } \\
\%\end{array}$ & $\begin{array}{c}\text { PPV } \\
\%\end{array}$ & $\begin{array}{c}\text { NPV } \\
\%\end{array}$ \\
\hline $\begin{array}{c}\text { Schumacher } \\
\text { et al. }^{46}\end{array}$ & 1985 & 106 & $>36$ & Minolta & $>=220$ & 94 & 78 & 44 & 99 \\
\hline $\begin{array}{c}\text { Gupta et } \\
a l^{47}\end{array}$ & 1991 & 77 & 37 to 42 & Icterometer & $>171$ & 97 & 71 & 78 & 96 \\
\hline $\begin{array}{c}\text { Linder et } \\
\mathrm{al}^{48}\end{array}$ & 1994 & 123 & $>37$ & Minolta 101 & $>220$ & 86 & 98 & 86 & 98 \\
\hline Dai et al..$^{61}$ & 1997 & 45 & $>37$ & Minolta & $>=260$ & 100 & 68 & 27 & 100 \\
\hline \multirow{2}{*}{$\begin{array}{c}\text { Rubaltelli et } \\
a_{l} .^{52}\end{array}$} & \multirow{2}{*}{2001} & \multirow{2}{*}{210} & \multirow{2}{*}{$\begin{array}{c}<=36 \text { and } \\
>36\end{array}$} & HPLC & $>220$ & 76 & 96 & 94 & 82 \\
\hline & & & & BiliCheck & $>220$ & 66 & 89 & 84 & 75 \\
\hline \multirow{2}{*}{$\begin{array}{c}\text { Wong et } \\
a_{l .}^{53}\end{array}$} & \multirow{2}{*}{2002} & \multirow{2}{*}{64} & \multirow{2}{*}{31 to 42} & Minolta & $>=170$ & 100 & 32 & 35 & NA \\
\hline & & & & BiliCheck & $>=150$ & 100 & 21 & 32 & NA \\
\hline \multirow{2}{*}{$\begin{array}{c}\text { Engle } e t \\
a l .\end{array}$} & \multirow{2}{*}{2002} & \multirow{2}{*}{304} & \multirow{2}{*}{$>35$} & BiliCheck & $>170$ & 73 & 97 & 99 & 50 \\
\hline & & & & BiliCheck & $>260$ & 33 & 96 & 82 & 75 \\
\hline $\begin{array}{l}\text { Amoozgar } \\
\text { H. et al. }\end{array}$ & 2007 & 209 & NA & Icterometer & NA & 94.7 & 55.2 & 85 & 95 \\
\hline $\begin{array}{c}\text { Leung T. et } \\
a l .56\end{array}$ & 2015 & 110 & NA & $\begin{array}{c}\text { Digital } \\
\text { photography }\end{array}$ & 162 & 100 & 50 & NA & NA \\
\hline \multirow{2}{*}{$\begin{array}{c}\text { Taylor J. et } \\
\text { al. }{ }^{39}\end{array}$} & \multirow[t]{2}{*}{2017} & \multirow[t]{2}{*}{530} & \multirow[t]{2}{*}{$>=35$} & \multirow[t]{2}{*}{ BiliCam } & $\begin{array}{c}\text { high-risk } \\
\text { zone }\end{array}$ & 84.6 & 75.1 & 32.2 & 97.2 \\
\hline & & & & & $>=290.7$ & 100 & 76.4 & 20.3 & 100 \\
\hline $\begin{array}{l}\text { Sadeghian } \\
\text { A. et al. }{ }^{63}\end{array}$ & 2017 & 280 & $36-39$ & BiliCheck & $>=251$ & 88.3 & 73.6 & 85.5 & 57.8 \\
\hline 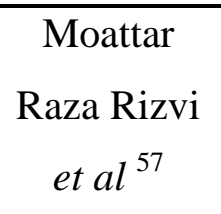 & 2018 & 100 & $35-42$ & BiliCapture & $>25$ & 92 & 75.6 & 47 & 99 \\
\hline $\begin{array}{l}\text { Munkholm } \\
\text { S. et al }\end{array}$ & 2018 & 64 & $>=35$ & $\begin{array}{c}\text { Smartphone- } \\
\text { based }\end{array}$ & $\begin{array}{c}>205 \text { (green } \\
\text { channel) }\end{array}$ & 100 & 62.5 & NA & NA \\
\hline
\end{tabular}




\begin{tabular}{|c|c|c|c|c|c|c|c|c|c|}
\hline & & & & method & $\begin{array}{c}>205 \text { (blue } \\
\text { channel) }\end{array}$ & 90.9 & 60 & NA & NA \\
\hline \multirow{2}{*}{$\begin{array}{c}\text { Outlaw F. et } \\
a l^{59}\end{array}$} & \multirow{2}{*}{2019} & \multirow{2}{*}{51} & \multirow{2}{*}{$35-41$} & \multirow{2}{*}{$\begin{array}{c}\text { neoSCB } \\
\text { application }\end{array}$} & $>250$ & 100 & 61 & 45 & 100 \\
\hline & & & & & $>205$ & 100 & 54 & 60 & 94 \\
\hline \multirow{2}{*}{$\begin{array}{l}\text { Padidar P. } \\
\text { et. al. }{ }^{18}\end{array}$} & \multirow{2}{*}{2019} & \multirow{2}{*}{113} & \multirow{2}{*}{$>=35$} & \multirow{2}{*}{$\begin{array}{c}\text { Android } \\
\text { OS-Based } \\
\text { Smartphone } \\
\text { Application }\end{array}$} & $<=171$ & 68 & 92.3 & NA & NA \\
\hline & & & & & $<=256.5$ & 82.1 & 100 & NA & NA \\
\hline \multirow{2}{*}{$\begin{array}{c}\text { Lee A. et al. } \\
34\end{array}$} & \multirow{2}{*}{2019} & \multirow{2}{*}{790} & \multirow{2}{*}{$>=35$} & \multirow{2}{*}{ Bili-ruler } & $\begin{array}{l}\text { TcB- } \\
>=290\end{array}$ & 94.1 & 85 & 22.5 & 99.7 \\
\hline & & & & & $\begin{array}{l}\text { TSB- } \\
>=290\end{array}$ & 81.4 & 83.4 & 58.5 & 94 \\
\hline
\end{tabular}

\section{CONCLUSION}

The proposed paper reviewed the recent developments in the detection of bilirubin levels. The most extensively used methods for bilirubin measurement are laboratory oriented, Direct Spectrophotometry and Transcutaneous Bilirubinometer. Each category of measurement has its own advantages and limitations. However, measurement of transcutaneous bilirubin (TcB) is most popular due to fast and reliable results and non-invasive in nature for verdict of hyperbilirubinemia. This article focuses on various available measurement techniques as witnessed from the volume of the last 50 years publication. Bare efforts have been taken to develop a sensitive and selective procedure in each group of methods but still achieving a precise, meticulous performance of any device is not accomplished to replace TSB measurement. The difference between TcB and TSB estimation need to reduce until the level of acceptance. Conversely, precise and accurate measurement of conjugated, unconjugated and free forms of bilirubin with intermediate metabolic products (biliverdin and other end products) in serum that has also intensified the research. 


\section{References}

[1] F. Ebbesen, L. M. Rasmussen, and P. D. Wimberley, "A new transcutaneous bilirubinometer, BiliCheck, used in the neonatal intensive care unit and the maternity ward," Acta Paediatr. Int. J. Paediatr., vol. 91, no. 2, pp. 203-211, 2002.

[2] C. Veenstra, W. Petersen, I. M. Vellekoop, W. Steenbergen, and N. Bosschaart, "Spatially confined quantification of bilirubin concentrations by spectroscopic visiblelight optical coherence tomography," Biomed. Opt. Express, vol. 9, no. 8, pp. 35813589, 2018.

[3] G. Paridhi, D. Nilesh, A. Sumit, W. Vinit, and P. Garg, "Study of Etiology of Neonatal Jaundice at tertiary care centre in Maharashtra," Sch. J. Appl. Med. Sci. Sch. J. App. Med. Sci, vol. 3, no. 4C, 2015.

[4] T. S. Leung et al., "Screening neonatal jaundice based on the sclera color of the eye using digital photography," Biomed. Opt. Express, vol. 6, no. 11, p. 4529, 2015.

[5] N. Ali, S. Z. M. Muji, A. Joret, R. Amirulah, N. Podari, and N. F. Dol Risep, "Optical technique for jaundice detection," ARPN J. Eng. Appl. Sci., vol. 10, no. 20, pp. 99299933, 2015.

[6] Ankan Gupta, A. Kumar, and P. Khera, "Jaundice Prediction through Non-Invasive Techniques: Issues and Challenges," IEEE INDICON, pp. 1-5, 2014.

[7] S. Vasava and P. P. Dagli, "Transcutaneous bilirubinometry: measurement site Influence of gestational age and," vol. 47, no. 1, pp. 27-32, 2018.

[8] A. Wan, S. Mat Daud, S. H. Teh, Y. M. Choo, and F. M. Kutty, "Management of neonatal jaundice in primary care.," Malaysian Fam. physician Off. J. Acad. Fam. Physicians Malaysia, vol. 11, no. 2-3, pp. 16-19, 2016.

[9] A. A. of Pediatrics, "Management of Hyperbilirubinemia in the Newborn Infant 35 or More Weeks of Gestation," Pediatrics, vol. 114, no. 1, 2004. 
[10] H. Baharuddin, M. S. Sulong, A. Joret, and T. A. Rahman, "Bile Pigments Detection via IR Sensor,” Proc. EnCon2010, pp. 3-5, 2010.

[11] H. Rate, "Women and Newborn Health Service Neonatal Observations," Neonatal Clin. Guidel. - Jaun. Quick Ref. Guid., pp. 1-5, 2017.

[12] E. Bhutani, VK, Johnson, L, Sivieri, "Predictive Ability of a Predischarge Hourspecific Serum Bilirubin for and Near-term Newborns, ” Pediatrics, vol. 103, no. 1, pp. 6-14, 1999.

[13] D. P. V. Puppalwar, "Review on 'Evolution of Methods of Bilirubin Estimation,", IOSR J. Dent. Med. Sci., vol. 1, no. 3, pp. 17-28, 2012.

[14] L. Ngashangva, V. Bachu, and P. Goswami, "Development of new methods for determination of bilirubin, ” J. Pharm. Biomed. Anal., vol. 162, pp. 272-285, 2019.

[15] K. Uma, J. Revathi, and J. Anitha, Telemetry System for Early Detection of Hyperbilirubinemia in Neonates. Elsevier Inc., 2019.

[16] and W. H. M. P. PETER L. M. JANSEN, H. THEO CUYPERS, "Quantitation of bilirubin conjugates $w$ it h hig h-performance," Eur. J. Clin. Invest., no. 1 984, pp. 295-300, 1984.

[17] A. S.-H. T. NAN-YU CHENG, YI-LING LIN, MING-CHIEN FANG, WEN-HSIEN LU, CHIN-CHIEH YANG, "Noninvasive transcutaneous bilirubin assessment of neonates with hyperbilirubinemia using a photon diffusion theory-based method," Biomed. Opt. Express, vol. 10, no. 6, p. 2969, 2019.

[18] K. S. N. and S. P. Pouria Padidar, Mohammadamin Shaker, Hamid Amoozgar, Mohammadhossein Khorraminejad-Shirazi, Fariba Hemmati, "Detection of neonatal jaundice by using an android OS-based smartphone application," Iran. J. Pediatr., vol. 29, no. 2, p.e84397, 2019.

[19] T. M. Slusher, A. Zipursky, and V. K. Bhutani, "A Global Need for Affordable 
Neonatal Jaundice Technologies," Semin. Perinatol., vol. 35, no. 3, pp. 185-191, 2011.

[20] G. Nagar, B. Vandermeer, S. Campbell, and M. Kumar, "Reliability of Transcutaneous Bilirubin Devices in Preterm Infants: A Systematic Review," Pediatrics, vol. 132, no. 5, pp. 871-881, 2013.

[21] A. S. Hussain et al., "Effectiveness of transcutaneous bilirubin measurement in managing neonatal jaundice in postnatal ward of a tertiary care hospital in Pakistan," BMJ Paediatr. Open, vol. 1, no. 1, p. e000065, 2017.

[22] S. N. El-Beshbishi, K. E. Shattuck, A. A. Mohammad, and J. R. Petersen, "Hyperbilirubinemia and transcutaneous bilirubinometry," Clin. Chem., vol. 55, no. 7, pp. 1280-1287, 2009.

[23] M. Mussavi, P. Niknafs, and B. Bijari, "Determining the correlation and accuracy of three methods of measuring neonatal bilirubin concentration," Iran. J. Pediatr., vol. 23, no. 3, pp. 333-339, 2013.

[24] B. O. Olusanya, D. O. Imosemi, and A. A. Emokpae, "Differences Between Transcutaneous and Serum Bilirubin Measurements in Black African Neonates," Pediatrics, vol. 138, no. 3, pp. e20160907-e20160907, 2016.

[25] A. Robertson, “Original Article Improved Transcutaneous Bilirubinometry:," J. Perinatol., vol. 22, pp. 12-14, 2002.

[26] W. D. Engle, G. L. Jackson, D. Sendelbach, D. Manning, and W. H. Frawley, "Assessment of a Transcutaneous Device in the Evaluation of Neonatal Hyperbilirubinemia in a Primarily Hispanic Population," Pediatrics, vol. 110, no. 1, pp. 61-67, 2004.

[27] S. Touch et al., "Evaluation of a New Transcutaneous Bilirubinometer," Pediatrics, vol. 113, no. 6, pp. 1628-1635, 2004. 
[28] Y. Yamauchi and I. Yamanouchi, "Transcutaneous Bilirubinometry: Effect of Postnatal Age," Pediatr. Int., vol. 33, no. 5, pp. 663-667, 1991.

[29] C. M. da Conceição, M. F. P. da S. Dornaus, M. A. Portella, A. D. Deutsch, and C. M. Rebello, "Influence of assessment site in measuring transcutaneous bilirubin," Einstein (São Paulo), vol. 12, no. 1, pp. 11-15, 2015.

[30] N. Purcell and P. J. Beeby, "The influence of skin temperature and skin perfusion on the cephalocaudal progression of jaundice in newborns: ORIGINAL ARTICLE, "J. Paediatr. Child Health, vol. 45, no. 10, pp. 582-586, 2009.

[31] P. A. Keahey et al., "Point-of-care device to diagnose and monitor neonatal jaundice in low-resource settings," Proc. Natl. Acad. Sci., p. 201714020, 2017.

[32] “Making a Transcutaneus Icterometer in Neonates," Iran. J. Pediatr., vol. 17, no. Suppl 2, pp. s224-s230, 2007.

[33] B. O. Olusanya, T. M. Slusher, D. O. Imosemi, and A. A. Emokpae, "Maternal detection of neonatal jaundice during birth hospitalization using a novel two-color icterometer," PLoS One, vol. 12, no. 8, pp. 1-11, 2017.

[34] A. C. Lee et al., "A Novel Icterometer for Hyperbilirubinemia Screening in LowResource Settings, ” Pediatrics, vol. 143, no. 5, p. e20182039, 2019.

[35] T. S. Leung, F. Outlaw, L. W. MacDonald, and J. Meek, “Jaundice Eye Color Index (JECI): quantifying the yellowness of the sclera in jaundiced neonates with digital photography," Biomed. Opt. Express, vol. 10, no. 3, p. 1250, 2019.

[36] F. Outlaw, J. Meek, L. W. MacDonald, and T. S. Leung, "Screening for Neonatal Jaundice with a Smartphone,” Proc. 2017 Int. Conf. Digit. Heal. - DH '17, pp. 241$242,2017$.

[37] S. Leartveravat, "by digital,” vol. 24, no. 1, pp. 105-118.

[38] M. Aydın, F. Hardalaç, B. Ural, and S. Karap, "Neonatal Jaundice Detection 
System,” J. Med. Syst., vol. 40, no. 7, pp. 1-11, 2016.

[39] J. A. Taylor et al., "Use of a Smartphone App to Assess Neonatal Jaundice," Pediatrics, vol. 140, no. 3, p. e20170312, 2017.

[40] H. H. Falk and O. D. Jensen, "A machine learning approach for jaundice detection using color corrected smartphone images," no. June, 2018.

[41] H. Kolunen, "Brief reports - Tiedonantoja," no. 10, pp. 2-3, 1984.

[42] N. Y. Boo et al., "The point-of-care Bilistick method has very short turn-around-time and high accuracy at lower cutoff levels to predict laboratory-measured TSB," Pediatr. Res., no. January, 2019.

[43] C. D. C. Zabetta et al., "Bilistick: A low-cost point-of-care system to measure total plasma bilirubin," Neonatology, vol. 103, no. 3, pp. 177-181, 2013.

[44] R. E. Schumacher, J. M. Thornbery, and G. R. Gutcher, "Transcutaneous Bilirubinometry: A Comparison of Old and New Methods Individual Login Institutional Login, " pp. 1-5, 2020.

[45] A. Carceller-Blanchard, J. Cousineau, and E. E. Delvin, "Point of care testing: Transcutaneous bilirubinometry in neonates," Clin. Biochem., vol. 42, no. 3, pp. 143149, 2009.

[46] N. T. R. M. Chaibva, A. Fenner, and J. Wolfsdorf, "Reliability of an icterometer in black neonates with hyperbilirubinaemia," South African Med. J., vol. 48, no. 36, pp. 1533-1534, 1974.

[47] I. Yamanouchi, Y. Yamauchi, and I. Igarashi, "Transcutaneous bilirubinometry: Preliminary studies of noninvasive transcutaneous bilirubin meter in the Okayama National Hospital," Pediatrics, vol. 65, no. 2, pp. 195-202, 1980.

[48] E. Schumacher and R. Gutcher, "Transcutaneous A Comparison," vol. 76, no. 1, 2018. 
[49] P. C. Gupta, S. Kumari, D. N. Mullick, and U. B. Lal, "Icterometer: a useful screening tool for neonatal jaundice.," Indian pediatrics, vol. 28, no. 5. pp. 473-476, 1991.

[50] N. Linder et al., "Noninvasive Determination of Neonatal Hyperbilirubinemia: Standardization for Variation in Skin Color," Am. J. Perinatol., vol. 11, no. 3, pp. 223-225, 1994.

[51] A. Knudsen and F. Ebbesen, "Transcutaneous bilirubinometry in neonatal intensive care units," Arch. Dis. Child., vol. 75, no. 1 SUPPL., 1996.

[52] K. L. Tan, H. P. Chia, and B. C. Koh, "Transcutaneous bilirubinometry in Chinese, Malay and Indian infants," Acta Paediatr. Int. J. Paediatr., vol. 85, no. 8, pp. 986990, 1996.

[53] R. Tayaba, D. Gribetz, I. Gribetz, and I. R. Holzman, "Noninvasive estimation of serum bilirubin.," Pediatrics, vol. 102, no. 3, 1998.

[54] F. F. Rubaltelli et al., "Transcutaneous bilirubin measurement: A multicenter evaluation of a new device," Pediatrics, vol. 107, no. 6, pp. 1264-1271, 2001.

[55] O. Article, "SpectRx BiliCheck versus Minolta AirShields," Measurement, pp. 137140, 2002.

[56] S. C. Kazmierczak, A. F. Robertson, K. P. Briley, B. Kreamer, and G. R. Gourley, "Transcutaneous Measurement of Bilirubin in Newborns: Comparison with an Automated Jendrassik-Grof Procedure and HPLC," Clin. Chem., vol. 50, no. 2, pp. 433-435, 2004.

[57] L. de Greef et al., "Bilicam: using mobile phones to monitor newborn jaundice," Proc. 2014 ACM Int. Jt. Conf. Pervasive Ubiquitous Comput., pp. 331-342, 2014.

[58] T. S. Leung et al., "Screening neonatal jaundice based on the sclera color of the eye using digital photography,” Biomed. Opt. Express, vol. 6, no. 11, p. 4529, 2015.

[59] M. R. Rizvi, F. M. Alaskar, R. S. Albaradie, N. F. Rizvi, and K. Al-Abdulwahab, "A 
novel non-invasive technique of measuring bilirubin levels using bilicapture," Oman Med. J., vol. 34, no. 1, pp. 26-33, 2019.

[60] S. B. Munkholm, T. Krøgholt, F. Ebbesen, P. B. Szecsi, and S. R. Kristensen, "The smartphone camera as a potential method for transcutaneous bilirubin measurement," PLoS One, vol. 13, no. 6, pp. 1-11, 2018.

[61] F. Outlaw, M. Nixon, O. Odeyemi, L. W. MacDonald, J. Meek, and T. S. Leung, "Smartphone screening for neonatal jaundice via ambient-subtracted sclera chromaticity: neoSCB app pilot study, ” PLoS One, 2019.

[62] A. Halder et al., "A Novel Whole Spectrum-based Non-invasive Screening Device for Neonatal Hyperbilirubinemia," IEEE J. Biomed. Heal. Informatics, no. January, pp. $1-1,2019$.

[63] J. Dai, D. M. Parry, and J. Krahn, "Transcutaneous bilirubinometry: Its role in the assessment of neonatal jaundice," Clin. Biochem., vol. 30, no. 1, pp. 1-9, 1997.

[64] W. D. Engle, G. L. Jackson, D. Sendelbach, D. Manning, and W. H. Frawley, "Assessment of a transcutaneous device in the evaluation of neonatal hyperbilirubinemia in a primarily Hispanic population," Pediatrics, vol. 110, no. 1 I, pp. 61-67, 2002.

[65] "Validation of Transcutaneous Bilirubinin Comparison with Serum Bilirubin for the Detection of Hyperbilirubinemia in Neonates, ” Int. J. Heal. Stud., vol. 3, no. 3, pp. 29$32,2018$. 
